\title{
PREVALENSI KECACINGAN DAN SATUS GIZI PADA ANAK SEKOLAH DASAR DI WILAYAH KERJA PUSKESMAS NUSA PENIDA (NP) III, KLUNGKUNG, BALI
}

\author{
Dwi Wahyuni $^{(1)}$, Yuyun Kurniawati ${ }^{(2)}$ \\ Program studi S1 Kesehatan Masyarakat Universitas MH.Thamrin \\ dwiwahyuni1102@gmail.com
}

\begin{abstract}
ABSTRAK
Kecamatan Nusa Penida merupakan bagian dari Kabupaten Klungkung yang aksesnya harus ditempuh dengan menyeberangi lautan, infrastruktur yang masih perlu pengembangan, sanitasi yang masih kurang serta status gizi anak sekolah dasar yang belum optimal. Temuan kasus ibu hamil yang muntah cacing di Dusun Dungkap 1 Desa Batukandik pada bulan April 2017 menandakan wilayah tersebut endemis kecacingan dan prevalensi kecacingan di Provinsi Bali sebesar 24\%. Penelitian ini bertujuan untuk mengetahui prevalensi kecacingan dan status gizi serta kadar Hemoglobin pada anak sekolah dasar di wilayah kerja Puskesmas Nusa Penida (NP) III, Kabupaten Klungkung, Bali. Penelitian dilakukan di Wilayah Kerja Puskesmas Nusa Penida ((NP) III dengan sampel penelitian adalah 44 siswa/siswi anak sekolah dasar negeri di empat desa (Batukandik, Klumpu, Batumadeg dan Sakti), masing-masing desa diambil 11 orang anak dengan menggunakan metoda random sampling. Pengumpulan data diperoleh dengan melakukan pengambilan sampel tinja, pengukuran Berat dan Tinggi Badan serta pengambilan darah. Hasil penelitian diperoleh bahwa tidak ditemukan kejadian kecacingan pada Anak Sekolah Dasar di 4 Desa yang terpilih, hal ini dikarenakan Anak Sekolah Dasar yang berada di Wilayah Kerja Puskesmas Nusa Penida III telah mendapatkan obat pencegahan kecacingan Abendazol 400 mg secara massal sebelum pengumpulan data dilakukan. Status Gizi siswa dengan indikator TB/U kategori pendek/stunting 36,4\%, Status Gizi dengan indikator IMT/U kategori "Normal" 93,2\% dan terdapat anak dengan status gizi sangat kurus (4,5\%) dan obesitas (2,3\%). Status Anemia 70,5\%.
\end{abstract}

Kata Kunci : Kecacingan, Stunting, Anemia, Bali

\section{PENDAHULUAN}

Penyakit kecacingan tersebar luas di Indonesia, baik di pedesaan maupun di perkotaan, terutama banyak menyerang pada anak-anak. Diperkirakan di seluruh dunia lebih dari 1,5 milyar orang terinfeksi cacing usus Soil Transmitted Helmints (STH). Sementara di Indonesia Tahun 2015 tercatat angka prevalensi cacingan mencapai 28,12\%. (Kemenkes, 2015). Infeksi cacing ini dapat menyebabkan masalah kesehatan masyarakat, khususnya pada anak yang masih dalam usia sekolah dasar. (Ditjen P2PL, 2007). Akibat yang akan terjadi jika seorang anak menderita cacingan adalah gangguan pertumbuhan dan anemia. 30 persen masalah stunting adalah karena kecacingan.

Di Indonesia, anemia masih merupakan salah satu masalah gizi yang utama di Indonesia. (Arisman, 2009). Berdasarkan data WHO (2005) diketahui bahwa total keseluruhan penduduk dunia yang menderita anemia adalah 1,62 miliar orang dengan prevalensi anak sekolah yaitu 25,4\% dan menyatakan bahwa 305 juta anak sekolah di seluruh dunia menderita anemia. Anak usia sekolah merupakan generasi penerus dan menjadi investasi bangsa untuk masa yang akan datang. Kualitas suatu bangsa pada masa mendatang ditentukan oleh kualitas anak saat ini.

Bali merupakan provinsi dengan kasus penyakit sistiserkosis (cacing pita) tertinggi di Indonesia, Salah satu penyebarannya adalah melalui travelling (wisata) dan migrasi serta kegemaran masyarakat untuk mengonsumsi daging babi. (Simposium nasional tentang infeksi kulit tropis di Kuta, Badung (23/10/2016). Berdasarkan data dari Dinas Kesehatan Provinsi Bali tahun 2017 menyebutkan bahwa prevalensi cacingan di Bali masih dalam kelompok sedang yang masuk di kisaran 20-40 persen, tepatnya 24 persen. 
Kabupaten Klungkung merupakan salah satu Kabupaten yang terletak di Provinsi Bali. Pada tahun 2017 berdasarkan informasi dari Dinas Kabupaten Klungkung, telah dilaporkan adanya ibu hamil yang muntah cacing. Setelah diperiksa, hasil laboratorium menunjukkan bahwa ibu hamil tersebut terinfeksi cacing gelang (Ascaris lumbricoides) dan ditangani pihak Puskesmas Nusa Penida (NP) III. Ibu hamil yang terinfeksi cacing gelang tersebut berasal dari Dusun Dungkap 1, Desa Batukandik Kecamatan Nusa Penida. Desa Batukandik merupakan wilayah kerja Puskesmas Nusa Penida (NP) III. Salah satu penyebab terjadinya kecacingan adalah kondisi jamban. Kondisi jamban sehat yang masih rendah berpotensi terjadi penularan penyakit berbasis lingkungan dan perilaku. Ditemukannya indikasi kasus kecacingan pada orang dewasa tersebut, dikhawatirkan tinggi juga kasusnya pada anak-anak. Selama ini belum ada pemeriksaan rutin kecacingan oleh pihak Puskesmas NP III terhadap anak-anak sekolah dasar ataupun orang dewasa, hanya jika ada keluhan atau laporan dari warga, maka Puskesmas dapat menemukan kasus kecacingan. Dinas Kesehatan Kabupaten Klungkung sudah mempunyai program pemberian obat cacaing untuk anak usia 1-12 tahun bahkan cakupan pemberian obat kecacingan (Abendazole $200 \mathrm{mg}$ dan Abendazole $400 \mathrm{mg}$ ) sudah mencapai 90\%. Pemberian obat cacing serentak diberikan pada anak balita satu tahun sekali bersamaan dengan program pemberian vitamin A, begitu pula anak sekolah dasar diberikan setahun sekali yaitu pada bulan Agustus di sekolah mereka masing-masing. Pemberian obat cacing adalah sebagai bentuk tindakan pencegahan terjadinya peningkatan kasus kecacingan pada anak-anak, tetapi jika perilaku, kondisi lingkungan sekitar serta asupan makanan yang diberikan masih mendukung terkena kecacingan, maka ini yang perlu menjadikan perhatian bagi semua pihak.

\section{METODE}

Penelitian ini merupakan jenis penelitian observasional analitik dengan desain cross sectional. Wilayah Kerja Puskesmas NP III Kecamatan Nusa Penida, Kabupaten Klungkung, Provinsi Bali terdiri dari 6 Desa yaitu Batu kandik, Klumpu, Batumadeg, Bunga mekar, Sakti dan Toya pakeh. Penelitian ini dilakukan pada 4 Desa terpilih. Desa Batu Kandik termasuk dalam lokasi penelitian karena adanya kasus kecacingan pada ibu hamil yang mengindikasikan adanya endemis kecacingan. 3 Desa lain (Klumpu, Batumadeg, Sakti) terpilih salah satu alasannya adalah kondisi sanitasi lingkungannya. Jika dilihat dari kondisi jamban, diperoleh data kondisi jamban sehat di Desa Batu kandik (78,57\%), Klumpu (88,1\%), Batumadeg (83,33\%) dan Sakti $(91,43 \%)$.

Jumlah sampel yang dibutuhkan untuk penelitian ini dihitung dengan menggunakan rumus estimasi proporsi dengan presisi mutlak variabel dependen katagori satu populasi yaitu sebanyak 44 orang anak. Data primer diperoleh dari anak SD umur 7-12 tahun dengan di dampingi oleh orang tua. Dalam pengumpulan data dilakukan dengan metode wawancara melalui pengisian kuesioner yang telah dipersiapkan sebelumnya, observasi terhadap lingkungan dan pengukuran status gizi serta pengambilan fases dan darah.

Pemeriksaan sampel feses dilakukan di laboratorium Puskesmas Nusa Penida (NP) III, Kecamatan Nusa Penida Kabupaten Klungkung. Jumlah fases yang diambil sebanyak \pm 10 gram yang diambil sebanyak 1 kali. Fases diambil dan dimasukkan kedalam pot yang telah disediakan (tidak boleh bercampur dengan urin) dan tidak ada risiko yang membahayakan responden. Pengujian dilakukan dengan 1 tetes eosin 2\% disebelah tetesan feses. Penilain status gizi dilakukan dengan metode antropometri denngan pengukuran Berat badan dan tinggi badan. Pemeriksaan sampel darah dilakukan untuk mengetahui kadar haemoglobin darah responden. Pengambilan 
darah hanya dilakukan 1 kali oleh tenaga kesehatan berpengalaman. Pada saat pengambilan darah akan ada sedikit rasa nyeri seperti digigit semut namun tidak ada risiko yang membahayakan. Jumlah darah yang diambil adalah sebanyak 0,2 $\mathrm{ml}$ melalui darah kapiler yaitu dibagian ujung jari anak/responden. Pengujian dilakukan dengan metode sahli. Data dianalisa dengan menggunakan perangkat lunak untuk melihat prevalensi kecacingan dan status gizi. Hasil disajikan dalam bentuk narasi dan tabulasi.

\section{HASIL}

Penelitian ini hanya diambil 44 anak, mengingat dana, tenaga dan waktu yang diperlukan tidak memungkinkan untuk meneliti seluruh anak sekolah dasar yang ada di 4 desa di wilayah kerja Puskesmas Nusa Penida III. Pemeriksaan kecacingan duplo hanya dilakukan pada kasus-kasus tertentu seperti adanya kadar $\mathrm{Hb}$ pada anak rendah dibawah $11 \mathrm{mg} / \mathrm{dl}$.

Penelitian ini dilaksanakan di Pulau Nusa Penida. Untuk sampai ke lokasi, harus melewati lautan terlebih dahulu. Jarak antara Klungkung dengan Nusa Penida sekitar 1-2 jam dengan menggunakan boat tergantung dari kondisi cuaca dan ombak. Lokasi 4 Sekolah yang menjadi sample penelitian ini terletak dekat dengan Puskesmas Nusa Penida III dengan menempuh jalan berbukit. Prevalensi Kejadian kecacingan pada Anak Sekolah Dasar diperoleh dengan pemeriksaan feses yang dilakukan oleh petugas pengumpul data dari puskesmas Nusa Penida III dengan metode eosin 2\%. pemeriksaan kecacingan dilakukan pada anak Sekolah Dasar di SDN 02 Klumpu, SDN 01 Sakti, SDN 01 Batu Kandik dan SDN 01 Batu Madeg. Hasil pemeriksaan menunjukkan bahwa prevalensi kecacingan pada Anak Sekolah Dasar di 4 Sekolah Dasar di Wilayah Kerja Puskesmas Nusa Penida III, Klungkung, Bali, Tahun 2018 adalah tidak ada atau nol. Untuk lebih meningkatkan keakuratan data tentang kecacingan, Kami melakukan pemeriksaan kembali (duplo) akan tetap karena keterbatasan dana dan tenaga, pemeriksaan feses hanya dilkukan sebanyak 50\% dari jumlah responden. Dan hasil yang diperoleh tetap sama yaitu tidak ditemukannya feses yang mengandung cacing dan dapat diartikan bahwa kasus kecacingan pada anak SD Wilayah Kerja Puskesmas Nusa Penida III, Klungkung, Bali, Tahun 2018 adalah tidak ada atau nol.

Berdasarkan pengukuran status gizi yaitu Tinggi badan dan berat badan terhadap 44 orang anak sekolah dasar diperoleh hasil bahwa sebesar 36,4\% (16 orang) anak sekolah dasar mempunyai status gizi pendek (stunting) dan terdapat anak sekolah dasar yang mempunyai status gizi sangat pendek yaitu sebesar 4,5\% (2 orang) sedangkan status gizi normal berdasarkan TB/U ada sebesar 59,1\% (26 orang). Status Gizi dengan indikator IMT/U kategori "Normal" 93,2\% dan terdapat anak dengan status gizi sangar kurus (4,5\%) dan obesitas (2,3\%). 
Tabel 1.

Status Gizi Responden Anak Sekolah Dasar di 4 Sekolah Dasar di Wilayah Kerja Puskesmas Nusa Penida III, Klungkung, Bali, Tahun 2018

\begin{tabular}{lcc}
\hline \multicolumn{1}{c}{ Status Gizi } & N & Frekuensi (\%) \\
\hline Status Gizi (TB/U) & & \\
\hline Sangat Pendek & 2 & 4.5 \\
Pendek & 16 & 36.4 \\
Normal & 26 & 59.1 \\
\hline IMT/U & & \\
\hline Sangat Kurus & 2 & 4.5 \\
Normal & 41 & 93.2 \\
Obesitas & 1 & 2.3 \\
\hline
\end{tabular}

Sumber: data primer hasil pengukuran tinggi badan, Berat Badan dan umur responden, tahun 2018

Status anemia pada anak sekolah dasar pada penelitian ini menggunakan klasifikasi dari standar WHO.

Berdasarkan hasil pemeriksaan darah terhadap 44 orang anak SD diperoleh bahwa sebesar $68,2 \%$ anak sekolah dasar menderita anemia ringan $(\mathrm{Hb}=9-10 \mathrm{gr} \%)$ dan terdapat sekitar $2,3 \%$ anemia sedang $(\mathrm{Hb}=7-8 \mathrm{gr} \%)$.

Tabel 2.

Gambaran Status Anemia Berdasarkan Pemeriksaan Hemoglobin (Hb) Anak Sekolah Dasar di 4 Sekolah Dasar di Wilayah Kerja Puskesmas Nusa Penida III, Klungkung, Bali, Tahun 2018

\begin{tabular}{lcc}
\hline \multicolumn{1}{c}{ Kelompok Hb } & Jumlah & $\boldsymbol{\%}$ \\
\hline Normal & 13 & 29.5 \\
Anemia Ringan & 30 & 68.2 \\
Anemia Sedang & 1 & 2.3 \\
\multicolumn{2}{c}{ Total } & $\mathbf{4 4}$ \\
Sumber: hasil pemeriksaan laboratorium Puskesmas NP III, tahun 2018
\end{tabular}

\section{PEMBAHASAN}

Tidak ditemukannnya kasus kecacingan pada Anak sekolah dasar di wilayah kerja NP dikarenakan semua Anak Sekolah Dasar yang berada di Wilayah Kerja Puskesmas Nusa Penida III telah mendapatkan Obat Pencegahan Secara Massal Cacingan yaitu jenis Abendazol sebelum pengumpulan data dilakukan. Abendazol merupakan Obat yang bekerja dengan menghambat pembentukan energi cacing sehingga mati. Maka dimungkinkan tidak ada lagi telur cacing maupun cacing dewasanya pada hasil pemeriksaan feses anak-anak sekolah dasar pada sampel di penelitian ini. Berdasarkan data dari Puskesmas Nusa Penida ((NP) III tahun 2015 bahwa pada anakanak prevalensi kecacingan berkisar $>10 \%$. Prevalensi ini tercatat hanya berdasarkan pasien yang berobat saja dan belum pernah dilakukannya penjaringan kasus kecacingan. Dinas Kesehatan sudah melakukan program pemberian obat cacing pada balita dan anak sekolah dasar secara rutin tiap tahun. Pada tahun 2017 dan 2018, Puskesmas Nusa Penida tidak mempunyai Data mengenai angka kejadian kecacingan khususnya pada Anak usia sekolah. Pemberian obat cacing dilakukan secara masal tanpa didahului dengan penjaringan terlebih dahulu. Berdasarkan peraturan menteri kesehatan Republik Indonesia Nomor 15 tahun 2017 tentang penanggulangan kecacingan bahwa Penemuan kasus Cacingan dilakukan secara aktif melalui penjaringan anak sekolah dasar atau madrasah ibtidaiyah dan secara pasif melalui penemuan kasus berdasarkan laporan pasien yang berobat di fasilitas pelayanan kesehatan dengan pemeriksaan sampel tinja. Survei prevalensi Cacingan sebagaimana dimaksud pada ayat (1) huruf c dilaksanakan melalui pemeriksaan tinja secara terpilih (sampling) pada anak 
sekolah dasar atau madrasah ibtidaiyah. Adapun tujuan Penanggulangan Cacingan adalah untuk menurunkan prevalensi Cacingan pada anak balita, anak usia pra sekolah dan anak usia sekolah dasar atau madrasah ibtidaiyah sebesar 10\% secara bertahap dan meningkatkan cakupan POPM (Pemberian Obat Pencegahan Massal) Cacingan minimal 75\%. Kelompok umur yang menjadi sasaran dalam program Penanggulangan Cacingan adalah balita, anak usia pra sekolah dan anak usia sekolah. POPM Cacingan dilaksanakan dua kali dalam 1 (satu) tahun untuk daerah kabupaten/kota dengan prevalensi tinggi dan satu kali dalam 1 (satu) tahun untuk daerah kabupaten/kota dengan prevalensi sedang.

Prevalensi pendek (stunting) pada anak sekolah di Indonesia secara nasional tahun 2007 sebesar 36,8\% (Balitbangkes, 2007). Secara nasional prevalensi stunting 5-12 tahun di Indonesia sebesar 35,1\% terdiri dari 15,1\% sangat pendek dan $20 \%$ pendek. Masih tidak jauh berbeda dengan anak balita (Balitbangkes, 2010). Prevalensi stunting umur 5-12 tahun di Indonesia sebesar 30,7\% terdiri dari 12,3\% sangat pendek, dan pendek 18,4\% (Balitbangkes, 2013). pada penelitian ini diperoleh hasil anak denganstatus gizi indikator TB/U kategori pendek/stunting 36,4\%, Status Gizi dengan indikator IMT/U kategori sangat kurus (4,5\%) dan obesitas (2,3\%). Lebih dari sepertiga $(36,1 \%)$ anak Indonesia tergolong pendek ketika masuk sekolah, dan hal ini merupakan indikasi gangguan kurang gizi kronis. Prevalensi anak pendek ini semakin meningkat dan berkembang dengan bertambahnya usia, baik pada anak perempuan maupun anak laki-laki (Aritonang, 2010). selain dari status gizi yang belum optimal. Pada penelitian ini juga ditemukan prevalensi anemia juga cukup besar yaitu sekitar70,5\%. jik hal ini terus berlanjt maka akan berpengaruh pada kemampuan anak dalam proses belajar atau prestasi belajar. Anak sekolah merupakan sasaran strategis dalam perbaikan gizi masyarakat. Hal ini menjadi penting karena anak sekolah merupakan generasi penerus tumpuan bangsa sehingga perlu dipersiapkan dengan baik kualitasnya. Selain itu anak sekolah selalu mengalami pertumbuhan fisik dan mental yang sangat diperlukan guna menunjang kehidupannya dimasa datang. Oleh karena itu guna mendukung keadaan tersebut diatas anak sekolah memerlukan kondisi tubuh yang optimal dan bugar, sehingga memerlukan status gizi yang baik (Depkes, 2001).

\section{KESIMPULAN DAN REKOMENDASI}

Dari hasil penelitian dapat disimpulkan bahwa Tidak ditemukannya kasus kecacingan pada Anak sekolah Dasar di empat desa yaitu Batukandik, Klumpu, Batumadeg dan Sakti dikarenakan anak Sekolah Dasar yang menjadi sampel penelitian sudah mendapatkan obat abendazol pada bulan Maret. Pemberian obat abendazol merupakan program pemerintah untuk seluruh masyarakat yang berada di Provinsi Bali termasuk Nusa Penida, Instrumen yang digunakan untuk melakukan pemeriksaan cacing adalah dengan menggunakan metode eosin $2 \%$, sehingga pemeriksaan tidak dapat melihat secara kuantitatif maupun kualitatif dari sampel feses yang dikumpulkan. Pemeriksaan kecacingan tidak dapat dilakukan dengan menggunakan metode apung dan metode kato, hal ini disebabkan laboratorium di Provinsi Bali hanya menggunakan metode Eosin 2\%, Gambaran Status Gizi siswa berdasarkan pengukuran Tinggi badan dengan indikatir TB/U kategori pendek/stunting sebesar 36,4\%, Status Gizi berdasarkan pengukuran Tinggi badan dan Berat badan dengan indikator IMT/U kategori normal sebesar 93,2\% dan Gambaran Status Anemia berdasarkan pemeriksaan Hemoglobin diperoleh, sebesar 70,5\% siswa menderita Anemia $(<10 \mathrm{gr} \%)$. Adapun saran yang dapat disampaikan oleh peneliti adalah Pemerintah daerah 
mampu menjaring kasus prevalensi kecacingan terlebih dahulu sebelum pemberian obat abendazole, sehingga perubahan ataupun penurunan kasus kecacingan akibat dari pemberian obat abendazole tersebut dapat terlihat keefektifannya, Pemerintah daerah khususnya dinas terkait (dinas kesehatan dan jajaran di bawahnya) dapat memberikan sosialisasi atau penyuluhan kepada masyarakat seperti PHBS yang menitikberatkan kepada perubahan budaya/perilaku buang air besar sembarangan, ataupun kampanye sanitasi/sejenisnya, yang dilakukan secara terus menerus sampai terciptanya kesadaran masyarakat secara mandiri dalam buang air besar di jamban dan pembuatan jamban yang saniter, Penyuluhan penularan penyakit kecacingan dan pencegahannya di tingkat sekolah dasar serta masyarakat sekitar agar mampu mengendalikan terjadinya penyebaran penyakit kecacingan, Penyelenggaraan penjaringan kasus kecacingan dibarengi dengan penyediaan reagensia di laboratorium baik untuk pemeriksaan kualitas maupun kuantitas, sehingga pemerintah daerah dapat mengetahui tingkat keganasan atau keparahan penyakit kecacingan pada anak atau orang dewasa, Pemberian makanan tambahan bagi anak sekolah dasar dapat terus terjaga agar anak mendapatkan gizi cukup dan tidak menjadi stunting permanent dan Pemberian materi tentang anemia pada anak sekolah melalui mata pelajaran penjaskes dan pemberian leaflet tentang pengetahuan anemia serta pentingnya makanan bergizi dan seimbang

\section{UCAPAN TERIMA KASIH}

Ucapan terima kasih kami haturkan, Ka. LPPPM, Rektor Universitas MH. Thamrin yang telah menfasilitasi kami untuk mendapatkan dana penelitian ini. Kami juga mengucapkan terima kasih yang sebesar-besarnya kepada Pemda Kab. Klungkung, Dinas Kesehatan Kab. Klungkung, Kepala Puskesmas Nusa Penida III dan jajarannya serta semua pihak yang sudah ikut berpartisipasi dan bekerjasama sehingga proses penelitian ini dapat dilakukan.

\section{REFERENSI}

1. Aditama, T.Y. Pedoman Pengendalian Cacingan. Jakarta: Kementerian Kesehatan RI; 2012

2. Ahdal Tasbih M, dkk. Hubungan infestasi kecacingan dengan status gizi pada anak SDN Cambaya di wilayah pesisir Kota Makasar. Program Studi ilmu Gizi Fakultas Kesehatan Masyarakat Universitas Hasanuddin; 2014

3. Almatsier,S. Prinsip Dasar Ilmu Gizi. Jakarta: PT Gramedia; 2010.

4. Arikunto. Prosedur Penelitian Suatu Pendekatan Praktek. Edisi Revisi V. PT. Rineka Cipta. . Jakarta; 2002

5. Arisman.. Buku Ajaran Ilmu Gizi: Gizi Dalam Daur Kehidupan.ECG. Jakarta; 2009

6. Aritonang I. Menilai Status Gizi Sehat Optimal, Grafina Mediacipta. Jakarta; 2010

7. Balitbangkes. Laporan Hasil Riset Kesehatan Nasional 2010.Jakarta; Depertemen Kesehatan Republik Indonesia. (2010)

8. Balitbangkes. Laporan Hasil Riset Kesehatan Dasar 2013.Jakarta; Depertemen Kesehatan Republik Indonesia. (2013)

9. Charles D Siregar Pengaruh Infeksi Cacing Usus yang Ditularkan Melalui Tanah pada Pertumbuhan Fisik Anak Usia Sekolah Dasar Sari Pediatri, Vol. 8, No. 2, September 2006 
10. Direktorat Jenderal PP \& PL . Pedoman pengendalian kecacingan. Jakarta: Departemen Kesehatan RI $(2007$

11. Gandahusada, S.W. Pribadi dan D.I. Heryy Parasitologi Kedokteran. Fakultas kedokteran UI, Jakarta; 2000

12. Hardidjaja, Pinardi \& TM (1994). Penuntun Laboratorium Parasitologi Kedokteran. FKUI, Jakarta

13. Haryanti, E. (2002). Helmintologi Kedokteran. Bagian Parasitologi Fakultas Kedokteran USU. Medan

14. Kapti IN, Ariwati L, Sudarmaja M. Pengobatan penyakit cacing usus pada anak-anak SD 1 Belok Sidan, Kecamatan Petang, Bandung. Pengabdian Masy Udayana Mengabdi; hal 3(2); 2004

15. Kemenkes, Direktorat P2B2 Temu Media "Gerakan Waspada Cacingan, Untuk Indonesia Sehat dan Cerdas" 05 November 2015, Jakarta; 2015

16. Kementerian Kesehatan RI, Keputusan Menteri Kesehatan Republik Indonesia Nomor:1995/MENKES/SK/XII/2010 tentang Standar Antropometri Penilaian Status Gizi Anak. Jakarta. 2011

17. Mardiana, Djarismawati . Prevalensi cacing usus pada murid sekolah dasar wajib belajar pelayanan gerakan terpadu pengentasan kemiskinan daerah kumuh di wilayah DKI Jakarta. J Ekologi Kesehatan;hal 7(2):769-74; 2008

18. Napitupulu, T. dkk . Helmintologi Kedokteran. Laboratorium Parasitologi. FK. USU. Medan.; 2006

19. Onggowaluyo S, Ismid IS . Gangguan fungsi kognitif akibat infeksi cacing yang ditularkan melalui tanah. MKI; hal 48(5):198-204; 1998

20. Pasaribu S. Penentuan optimal pengobatan massal askariasis dengan Albendazole pada anak Sekolah Dasar di desa Suka. Ringkasan Disertasi. Program Pasca Sarjana USU Medan. 2004

21. Pemrop, Jawa Timur . Baku Antropometri WHO NCHS (Persen Terhadap Median). Akademi Gizi (AKZI). Surabaya; 2003

22. Supariasa IDN Dkk. Penilaian Status Gizi. Jakarta: EGC; 2012.

23. WHO.Worldwide prevalence of anaemia. 2005; Available from:http://apps.who.int/iris/bitstream/10665/43894/1/978924159657_eng.pd 